\title{
21
}

\section{The Security Model to Combine the Corporate and Information Security}

\author{
TEEMUPEKKA VIRTANEN \\ Helsinki University of Technology, Finland \\ Telecommunications Software and Multimedia Laboratory, \\ P.O Box 5400, FIN-02015, HUT, Finland \\ teemupekka.virtanen@hut.fi
}

Key words: security model, information security, corporate security

Abstract: There are two different areas of security that have been called the corporate security and the information security. Both of these areas have been organized in numerous ways. The lack of the common agreement of the security features and components has caused conflicts between security officers and IT people. Without a common structure it is also difficult to inspect and certify security. In this paper some of the existing approaches are presented and compared. This study is in a general level trying to find something one may call structure or organization of the security features.

We then present a new model that combines the corporate security and the information security. This model is based on the assets and security measures. The measures are divided into six sections that may be easily organized in a typical corporation.

\section{INTRODUCTION}

There have been several ways to organize information security. A good model is a tool to plan, educate and organize security. To be useful the model has to fit its purpose. It has to be a good logical unit and help to manage the whole area. These models have to change according the development of the information technology, business logic and organization structure. 
Security is a matter of culture, language and social environment [Yngström]. To be effective in improving the security the methods have to fit the local ways of thinking and organizing the work. The people also have to understand what they are doing and why. The lack of awareness of the users and managers is a problem that is very difficult to cover with technical equipments [James].

The security has to be a part of the business processes of the organization and people have a great role in these processes [Holbein]. The design of the processes is often a remarkable part of the assets of the organization. The documentation of these processes is often inadequate and lack of documentation is a threat for a organization.

There have been conflicts between security authorities and other managers in the organization. Security as a function covers so large area of the functions of the organization that situation is impossible without any restrictions. At the same time it is difficult to be sure that every aspects of the security have been taken into account if the definition or if the area of the security authorities has been reduced. Conflicts between security officers and information security officers are also common. The corporate security includes the information security and thus security officers tend to manage that area also. In the same time many areas of the information security belongs to the corporate security functions. So it is reasonable to assume that information security officers set demands on these functions.

There are several ways to organize corporate and information security. There might be a specific security department for the head of the security or security functions may be among the other administrative functions. Besides these alternatives the head of the information security may be also in the IT department.

When designing a secure system there have to be a model of security [Eckert]. Many of the models considered information security as computer security or information system security [Rannenberg], [Eloff]. In the ecommerce applications one has to take also other than technical aspects into account [Labuschagne], [De Win].

In this paper several security/information security models are presented. All the models are designed for specific purpose and that those purposes naturally have their effects in the model. Every organization has to select the model suitable for its needs and structure. The purpose of this paper is however to present a new model that combines the best parts of these models and specifically combine the corporate and information security into one solid entity. 


\section{SOME CURRENT MODELS}

\subsection{The Finnish governmental policy}

The actual model described here is from the Finnish governmental order about information security in the administration. This order was first time given in 1992 [Fin92] and revised in 1998 [Fin98].

The protection measures are divided into eight sections: Administrative security includes policies, principles, organization, duties, education and monitoring. Personnel security tries to minimize personnel risks with background checking, duties sharing, authorizations, personnel protection, education and monitoring. Data security includes availability, integrity, confidentiality and secure handling of the data. Physical security (environmental security) means protecting equipments, data and computer rooms from physical threats and damages. Hardware security includes all the security measures implemented by computer hardware. Software security includes all the security measures implemented by computer software. Communications security includes all the security measures that ensure availability, integrity and confidentiality of the information in the communication networks. Operations security is a security of daily duties (Figure 1).

\section{$2.2 \quad$ ISO-model (BS7799)}

The British Standard is based on PD 0003, a Code of practice for information security management, developed by the Department of Trade and Industry with the assistance of leading UK companies and organizations. The guidance in this code of practice is intended to be as comprehensive as possible. Not all controls described will be relevant to every situation. [ISO]

Security has to be embedded in the every day's business processes, with responsibilities for all people involved. The Code of Practice for Information security Management gives one practical guidelines in designing, implementing and assessing information security measures, in a technical, physical and organizational sense.

The code of practice is divided into 10 sections as follows: Security policy, security organization, classification and control, personnel security, environmental security, network management, system access control, system development and maintenance, business continuity planning and compliance 
Besides these sections there are 10 key controls that are either essential requirements or are considered to be fundamental building blocks for information security.

\section{$2.3 \quad$ CobiT-model}

Information Systems Audit and Control Foundation has made CobiT to help bridge the gaps between business risks, control needs and technical issues. It provides good practices across a domain and process framework and presents activities in manageable and logical structure. [COBIT]

To satisfy business objectives, information need to conform to certain criterias, which CobiT refers to as business requirements for information. There are quality requirements (quality, cost and delivery), fiduciary requirements (effectiveness \& efficiency of operation, reliability of information and compliance with laws and regulations) and security requirements (confidentiality, integrity and availability).

The CobiT framework consists of high-level Control Objectives and an overall structure for their classification. There are three levels of IT efforts. Starting at the bottom, there are activities and tasks needed to achieve the measurable result. Processes are then defined one layer up as a series of joined activities or tasks with natural control breaks. At the highest level, processes are naturally grouped together into domains. Their natural grouping is often confirmed as responsibility domains in an organizational structure and is in line with the management cycle or life-cycle applicable to IT processes.

The IT resources identified in CobiT are data, application systems, technology, facilities and people.

The definitions of the four domains are:

Planning and Organization : This domain covers strategy and tactics, and concerns the identification of the way IT can best contribute to the achievements of the business objectives.

Acquisition and Implementation: To realized the IT strategy, IT solutions need to be identified, developed or acquired as well as implemented and integrated into business process.

Delivery and Support: This domain includes the actual processing of data by application systems, often classified under application controls.

Monitoring: This domain addresses management's oversight of the organization's control process and independent assurance provided by internal and external audit (Figure 1). 


\subsection{The Finnish corporate security}

The Confederation of Finnish Industry and Employers has made several publications for the Finnish companies. A corporate security is one of the areas of those publications. In these publications there are a model in which corporate security is divided into several areas. This same model is also used by the Lifelong Learning Institute Dipoli (Helsinki University of Technology, HUT), in its education program for security managers. [Pesonen]

The corporate security is divided into several different areas. This dividing is based on the legislation of Finland that sets some security related duties to companies. Typically there must be a person in the company who is responsible to arrange these duties. Then there has to be a learning material and a course for these persons and that creates a new area into the security model (Figure 1).

Administrative security includes the security related legislation, security standards, relationship with officials, recruiting (security related matters) and PR (security related matters). Physical security includes buildings and the security monitoring in these buildings. Most of the crime preventing and monitoring activities in the building are part of physical security. Fire prevention and shelters includes fire prevention in buildings, fire extinguishers, fire detectors and shelter rooms for people Safety includes safety in the work and the health services. Personnel security includes the protection of own personnel and customers. Especially the key persons must be protected also during travel and in abroad. Environmental protection includes pollution prevention and the handling and storing of the dangerous or hazard chemicals. Transportation security includes the crime prevention during transportation and prevention of the road accidents. Security abroad includes the local legislation, connections to the local authorities and all the local actions. Emergency Supply includes sufficient facilities must be built up and maintained to ensure the production and output of goods and services in a wide spectrum of industries, in times of unusual conditions. [Supply Act]. Information security includes handling of the printed material, archiving, computer security, communication security and privacy protection. Risk management includes methods to manage risks, security analyses and insurances

There is not any connection to the goals of the organization and thus the corporate security according this model may fulfill mainly requirements that come outside the organization. 
3. ANALYZING THE CURRENT MODELS

\subsection{Analyses of the models}

All these security models described in the previous section have a specific purpose they are made for. Therefore one can't say they are wrong or have problems. However, it is difficult to create a solid model based on these models.

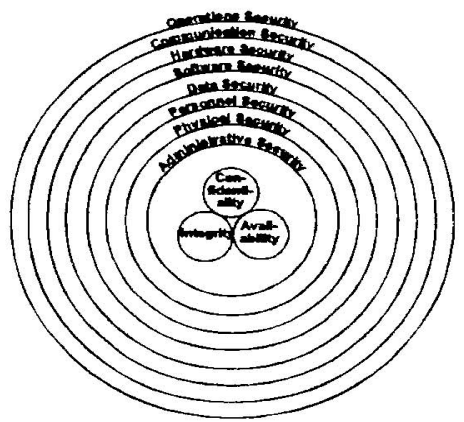

The Finnish governmental model

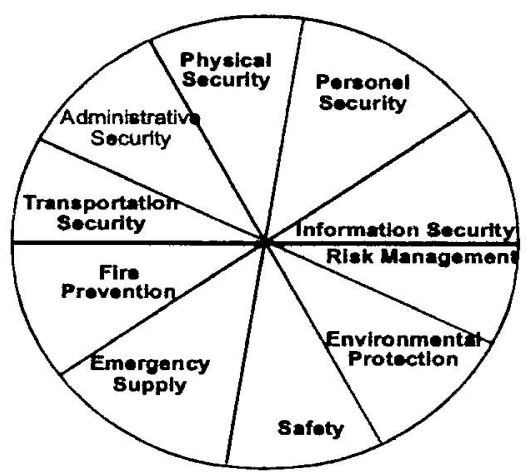

The Finnish corporate security

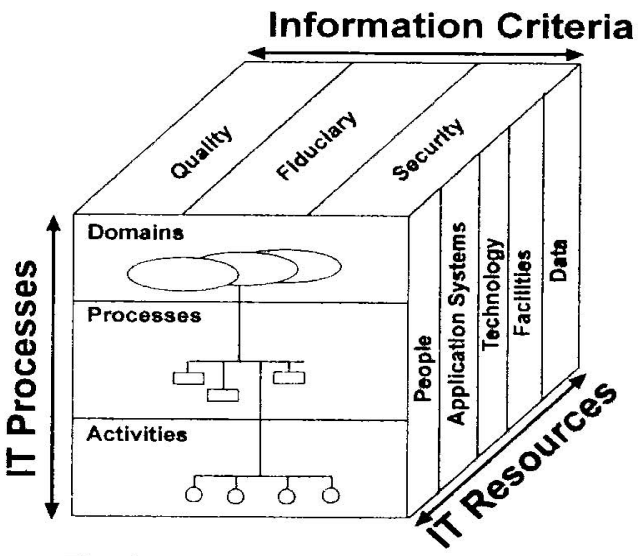

The CobiT-model

Figure 1. The current security models

The Finnish governmental policy for information security is oldfashioned. It fits better in the time of mainframes than modern client-server architecture where one can't make difference between hardware, software and network. 
The BSI-standard is a list of useful measures to improve information security and it makes very easy to qualify the level of the organization. Dividing these measures to the sections is not made systematically and therefore there is not any logical model of information security.

The Cobit-model has a strong live-cycle background. Every information system has a designing-, implementation- and daily work -phase. Inside these domains there are the processes where the actual security measures are. Each process has a list of resources, requirements and information criterias it fulfills. There are several points of view in these criteria and they are not formed a simple model. One can make this approach better by simplifying it more.

The Finnish corporate security -model is a model for a corporate security as a whole. The information security is only a part of it. I have taken it into this paper because I compare it with the model of pure information security and try to combine these both. The problem of this model is that there is not a proper connection between business needs and security. This model is made to fulfill the requirements coming from outside the organization. There is no coordination of these requirements and therefore there are many conflicts.

\subsection{Corporate security and information security}

There may easily be conflicts between corporate security and the information security if the responsibilities are not clear. One can ask if the information security is a part of the corporate security or vice versa. There have also been issues about whether the manager of the information security should be in the computer department or security department.

If we look at both the Finnish models, one for the corporate security and other for information security, we may notice that there are many common elements. In the corporate security there is one section for information security and in the information security there are several sections that exist also in the corporate security.

This conflict is based on the fact that actually the information security as a term is a combination of goal and measures. Basically the same conflict exists in the protection of environment. Graphically we can try to modify the original pie chart taking the information security out from the pie to the new layer in the top of the pie. 


\section{THE NEW MODEL}

The basic principle in the new model is that there are assets, threats and measures. The assets must be recognized and classified. The threats must be found out and analyzed. The measures must find out to prevent the threats or minimize the damages they caused.

\subsection{The assets}

There are four different types of assets: information, people, material and goodwill. These are not totally independent each other because people might actually be a storage of information and a pair of hands like a machine. If people are considered this way however, it will cause damage to the goodwill.

The value of the asset may come from several sources. It may be given outside the organization, like in the legislation, or the item may be crucial for the working process. Some items may have pure monetary value.

All the assets may be valuable by several ways. The confidentiality, availability and integrity are not only properties of information but the general classifying criteria. In a real life however, the availability is the most important property of all the other assets than information. In this context monetary value is same as the availability (to sell).

\subsection{The measures}

The measures are divided into six sections. They are

Security management is a link between business objects and security. In this process the security level needed for business is decided and also what is the risk an organization may take. The goals and the visions of the organization have an immediate effect to the security level. This is also the place to organize security functions in the organization.

Asset management is a process where the assets are found and classified.

Physical security (environmental security) prevents any physical threats that come from outside. There might be several security areas in the organization and everything that leaves one area and go into another must go through barrier of physical security. Normally physical security cannot help against a threat that already is in the area, but there are some exceptions: fire prevention systems work inside the perimeter and also the guard.

Personal security differs from the earlier models because it is not protecting people. Personal security protects all the assets using methods that affect people. In a recruiting situation one has to prevent the unsuitable 
people to be hired. The employees have to be capable and willing to work secure manner.

Computer security includes all the security functions of normal computers and communication. It might be implemented by software, hardware or separate devices. If the computer is built into special system so that it is invisible to the user or it is impossible to program, it is handled like a system without a computer. For example a fire detecting system may have a computer inside but because the computer can't do anything else control the system, it is not part of the computer security but physical security.

Work security connects security to the daily work. It is like a quality in the work avoiding accidents that may damage the assets. The routines of the work are planned so that there are no unnecessary losses.

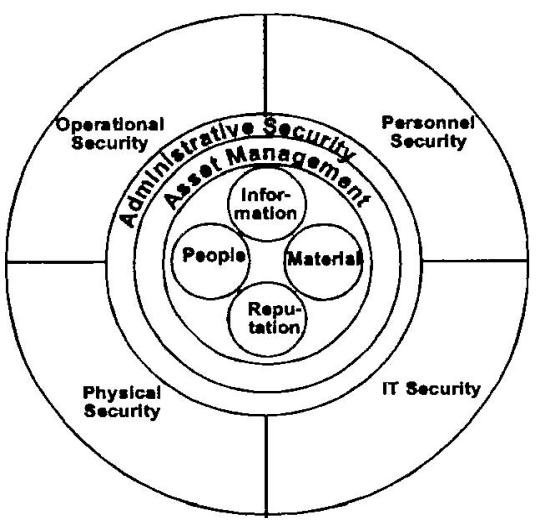

Figure 2. The new model

In a typical situation there is a room as a single security area. Security management has told what is the acceptable level of risk in this company. Asset management has told which items in the room are valuable. Personal security selects the people who are allowed to enter and educates them to work properly. Physical security prevents others to enter. Work security guarantees that the normal work of the allowed people do not cause any damage to the assets. Computer security takes care of the electrical universe. There might be connections to and from the room and computer security watches these. In the room there might be another room with its own security level and authorized people.

\section{THE ADVANTAGES OF THE NEW MODEL}

In this model there is clear solution between security and information security. There is no information security. There are only several protecting 
methods that are applied to secure assets. Information is one of the assets and is protected in a same way as the other assets are.

This model helps to avoid duplicate protecting systems. The existing system may protect all the assets and there don't have to be separate systems for different assets.

The sections are as independent each other as possible. This avoids conflicts between different parts of the organization.

The model is logical and easy to understand. That makes easy to describe the elements of the security and teach them to others.

The measures are easy to organize. Security management is a part of typical business management. Most of the decisions required are the same that are made when decide the business goals and methods. Personal security is a normal work of personal department like the computer security belongs to the computer department.

The physical security is a concrete section of security. In many cases there already is a security department managing these duties. However there might also be a department taking care of buildings and some of the duties in the physical security might have been there.

The work security is based on the normal hierarchy. A supervisor has to be sure that subordinates work in a secure way. These standards have to be essential part of any goal settings or orders. The work has also to be organized in a secure way. The worker has to have time and resources to finish the job without breaking the rules. The working procedures have to contain checking points and inspections to guarantee the quality of the work.

\section{CONCLUSION}

In this paper a new model is presented to organize security and information security. In this model the both areas are combined into a corporate security.

The assets are people, material, information and reputation. The value of the asset may be based on the availability, confidentiality or integrity of the asset. The classification principles may come from outside (legislation, reputation) or inside the organization (production requirements).

The reputation might be considered as a special case that is based on the compliance of the rules and regulations and might also achieve by adding the assets on outside the organization, for example instead protecting the own people only protect also the people in the neighborhood.

The protecting measurements are divided into four areas. This dividing is based on the normal organization of the corporation. This makes security 
functions as a part of the normal work of the people that normally carry out these tasks.

The model has been tested by using it some years in two nationwide organizations. It has simplified the security organization and maked it easier to write down security policy and requirements. One of these organizations has a security department that has divided into several sections according the functions. These sections coordinate the security functions in the other departments (personnel, computer, real property) and line organization. The other corporation has only a security manager that coordinates the security work in the corporation. This manager sets the standards of the corporation and consults the departments in the corporate headquarter and management in the divisions.

\section{REFERENCES}

[COBIT] CobiT Framework 2th edition, http://www.cobit.com, 1998

[De Win] De Win, B., Van den Bergh, J., Matthijs, F., De Becker, B., Joosen, W.: “A security architecture for electronic commerce applications", Information Security for Global Information Infrastructures (IFIP SEC 2000), pp. 491 - 500, Kluwer Academic Publisher, The Netherlands 2000, ISBN 0792379144

[Eckert] Eckert C.: "On Security Models", Information Systems Security (IFIP SEC '96), pp. 485 - 486, Chapman \& Hall, UK 1996, ISBN 0412781204

[Eloff] Eloff, M.M, von Solms, S.H:” Information Security: Process Evaluation and Product Evaluation", Information Security for Global Information Infrastructures (IFIP SEC 2000), 11 - 17, Kluwer Academic Publisher, The Netherlands 2000, ISBN 07923 79144

[Fin93] Valtioneuvoston periaatepäätös tietoturvallisuudesta (In Finnish), Ministry of Finance (of Finland), Finland 1993

[Fin98] Valtioneuvoston periaatepäätös tietoturvallisuudesta (In Finnish), Ministry of Finance (of Finland), Finland 1998

[Holbein] Holbein, R. et.al: "The use of Business Process Models for Security Design in Organisations”, Information Systems Security (IFIP SEC ‘96), pp 13 - 22,, Chapman \& Hall, UK 1996, ISBN 0412781204

[ISO] British Standard, Code of Practise for Information Security Management, BS7799:1995, British Standard, ISBN 058023642 0, 1995

[James] James, H. et. al: "A human approach to security management in HealthCare" Information Systems Security (IFIP SEC '96), pp 365 - 376, Chapman \& Hall, UK 1996, ISBN 0412781204

[Labuschagne] Labuschagne, L: "A framework for electronic commerce security" Information Security for Global Information Infrastructures (IFIP SEC 2000), pp. 441 454, Kluwer Academic Publisher, The Netherlands 2000, ISBN 0792379144

[Personen] Pesonen Markku: Yrityksen turvallisuusjärjestelyt (Security Arrangements of a Company), ISBN 952904705 3, Yliopistopaino, Finland, 1993

[Rannenberg] Rannenberg Kai: "IT Security Certification and Criteria", Information Security for Global Information Infrastructures (IFIP SEC 2000), pp 1 - 10, Kluwer Academic Publisher, The Netherlands 2000, ISBN 0792379144 
[Supply Act] Security of Supply Act, The Ministry of Defence, 1390/92, 1992

[Yngström] Yngström L.: "IT Security and Privacy Education", Information Systems

Security (IFIP SEC '96), pp. 351-364, Chapman \& Hall, UK 1996, ISBN 0412781204 